\title{
Research on the Construction of Human Resource Incentive Mechanism in Colleges
}

\author{
Jing $\operatorname{Xin}^{1, a}$ \\ ${ }^{1}$ Nanyang Institute of Technology, Nanyang, Henan, 473004 \\ ${ }^{a}$ email
}

Keywords: Incentive Mechanism, Human Resource, College Management

\begin{abstract}
Incentive mechanism is an important proposition in the work of human resource management in Colleges, and it is also an effective way to promote the quality of human resources management and the improvement of efficiency. It is very important to construct the university human resource management system based on the incentive theory, which can effectively mobilize the enthusiasm and creativity of the faculty and staff in Colleges so as to ensure the realization of the goal of human resource management. Therefore, the application of incentive theory in human resource management is very important.
\end{abstract}

\section{Introduction}

Human resources management in Colleges in the general sense refers to the Colleges through the continuous absorption of high knowledge of teachers, the teacher's ability to apply to the work of Colleges, and explore the potential of teachers to stimulate the enthusiasm of teachers in the work, Creativity and initiative, and ultimately the realization of all the goals in the development of Colleges. The human resources management of university teachers mainly studies the objective laws and internal links of the faculty and staff in the management process, and contains the following two points: First, the object of human resource management in Colleges is unique. The object of human resource management in Colleges is the relationship between teachers and researchers in the process of teaching and research, and the relationship between human and environment in the process. University teachers in the development of human resources in the continuous improvement in the use of constantly enrich. This is a perfect and rich, one is to promote the progress of human resources management and improve the other areas of human resources management development and progress played a certain role in promoting. Second, the human resource management of university teachers has a unique objective development law. The theory, method, purpose and means of human resource management in Colleges are developed with the progress of society. The management of human resources in Colleges is the prerequisite for deepening the personnel system of Colleges. It is the key to improve the quality of teaching, scientific research and optimize the teaching staff. The effective and positive incentive for teachers and outstanding scientific research personnel has become an important research content in the human resources management of Colleges.

\section{The Current Situation of Incentive Mechanism of Human Resource Management in Colleges}

College teachers are currently used in the past, most of the incentives used in the management, is a long-term formation, not sound, closed static management model, this management model is a management system can not keep pace with the times, Lack of incentives for individual teachers, in particular, do not focus on the psychological needs of teachers and other internal incentives analysis, leading to the human resources management incentive mechanism still has a lot of imperfect, unscientific place. Its main performance for the following aspects:

At present, want to become a college teacher must obtain a master's degree, the vast majority of Colleges need to obtain the appropriate doctoral degree, some Colleges even higher requirements. However, it takes a long time to obtain these degrees. To obtain a master's degree requires 6-7 years of study time, it takes at least 10 years to obtain a doctoral degree. To become a college teacher, the 
time cost and economic cost is great. But this time and economic input and college teachers in the work obtained after the reward is disproportionate, and there is a big gap between the two. Even the salary of college teachers is far less than other occupations. It can be seen that the remuneration of college teachers is not low, but with their pay is disproportionate. The current salary of college teachers is mainly composed of basic salary, performance pay and allowances and other benefits. Where the job wage is the implementation of the relevant provisions of the country, it is in accordance with the teacher's title, job level decision. Similarly, the performance wage is also directly related to the title and rank of the teacher; and the salary is calculated by the teacher's length of service, from the assistant to the professor, a total of 12 grades of wages, the lowest grade wage standards and very low. The welfare of teachers includes welfare measures such as fund raising, transportation subsidy and subsidy for heating, and some are allocated according to length of service, title, etc., and the other part is relatively evenly distributed. As a result, the number of teachers' salary income is mostly determined by the teacher's title, grade and length of service. The salary standard is relatively fixed, the increase is not big, the flexibility is poor and the implementation is strict. For young college teachers, the salary income and the corresponding benefits are relatively small, and the difficulty of improvement is not low, even for working for some time middle-aged teachers, pay and benefits and employees still have a big gap, It is difficult for teachers to be satisfied.

As a training to adapt to the needs of modern society as the main task of institutions of higher learning, but also bear the work of scientific research, and teachers is the mainstay of the daily operation of Colleges. Colleges as a place of education and scientific research, institutions of higher learning management should also have teaching and research personnel to manage. In terms of the actual situation, the enthusiasm of college teachers to participate in the management of Colleges to a certain extent is also very high, the university has become a topic of higher voice, but also a reform and development of Colleges in one direction. From the direction of inspiration, giving teachers more opportunities to participate in the management of school affairs, for the effective mobilization of teachers work enthusiasm and initiative, training teachers on the school's sense of belonging has a very important significance. In the process of design of incentive mechanism of human resources management in Colleges, we should pay attention to the channels of enlarging teachers 'participation in university management and satisfying teachers' management authority.

If the assessment system is not scientific, imperfect, it will not only play a stimulating role, but will bring pressure on teachers. In the assessment system, the level of teachers' teaching level, student evaluation played a very important role. Although the evaluation of teachers have a clear reference standard, but the evaluation of teachers for teachers often based on personal likes and dislikes, so in the evaluation process is the lack of objectivity, scientific, etc., for students, they evaluate teachers more concerned about the classroom of the atmosphere, but for the teaching of scientific, systematic and other scientific criteria for lack of attention. Therefore, students in the evaluation of the quality of teaching teachers is relatively one-sided, the lack of impartiality and comprehensiveness. And most of the evaluation indicators are quantitative standards, a single means of judgments, the lack of a comprehensive ability of teachers and the level of judgment, but also ignore the individual differences in teachers. After the students to evaluate, Colleges tend to use such as rank and reward and other related measures, the recognition of outstanding teachers, the failure of teachers to criticize, which makes part of the enthusiasm and creativity of teachers to a certain degree of containment.

\section{The Main Measures of Human Resource Management Incentive in Colleges}

Compensation incentives are one of the most basic incentives, and incentive incentives stimulate the enthusiasm of those who are motivated by satisfying the material interests of individuals or groups. In the economic society, no one can leave the material demand, material incentive is the most basic incentive way of human resource management incentive in Colleges. In the university human resource management, the salary incentive mainly manifests in the salary, the allowance and the research reward. 
The work itself is the nature of the incentive. Work motivation is to give people a platform, so that employees have the opportunity to be successful. For high-level intellectuals, work and career is the first need of life, work incentives themselves can provide such opportunities for college teachers. The motivation of college teachers' work includes the content of continuous enrichment, the improvement of job challenges, the promotion of job duties, the achievement of work performance, the development of work prospects, the participation of school management, etc., which are related to the content of work incentives.

The competition is in any organization, and he has the incentive to act on man, and the power of man is always in the state of excitement. Through the organization of internal competition, it can continue to promote the work of teachers. In our country Colleges, the university teachers generally implement the appointment system, as well as the Colleges set up the promotion system embodies the benign competition, so as to better stimulate the teacher's initiative. From another point of view, the incentive theory as the core of a series of promotion system, reward and punishment system is to continue through competition for teaching and research to provide good system regulations, which are competitive incentives.

Emotional motivation is an important part of personal inner motivation. To improve the efficiency of college staff and staff, only material incentives and other external incentives is not enough, but also to focus on the teacher's inner feelings. Emotion is the inner power of the individual, this internal power can play out how much depends on the outside world of personal feelings of stimulation, probation and so on. From the individual emotional incentive cut into, through the teacher's concern and trust, so as to mobilize the enthusiasm of teachers and stimulate the creativity of teachers. Emotional incentives in the trust and care are an important means of internal incentives, which includes teachers in the work of interpersonal relationships, organizational trust and attention, and the corresponding welfare rights.

Objective motivation is an important incentive measure in human resource management in Colleges. The goal is the teacher in the work of their own preset results, the goal of motivation is to mobilize the enthusiasm of the teacher's external driving force. The goal of the incentive function is to set the goal to drive teachers to the goal of continuous efforts to achieve the ultimate goal of individual, while achieving organizational goals. Objective incentives can guide teachers to behave in a way that aligns individual needs with organizational goals. The goal of the market economy is to focus on participation. The goal of the university management is to combine the development strategy and goal of the school with the individual development goals of the teachers. To achieve the goal incentive can make the teachers realize their own value and social responsibility so that teachers can really Integrate your goals into organizational goals.

The teacher's demand for knowledge is one of the most important needs of teachers in career development. According to the different needs of teachers, teachers provide learning, growth opportunities. Establish a sound training mechanism for teachers, and constantly provide teachers with opportunities for further study. Training can continuously update the teacher's knowledge structure system, understand the frontier knowledge of the discipline, improve the teachers 'scientific research ability and teaching level, meet the teachers' knowledge needs. Because teachers exist between individual differences, so the teacher's growth needs are not the same. Some need to further study of academic qualifications, and some need to improve in scientific research, and some need to master more skills, the school teacher training should be targeted through the training of teachers training needs, according to the school's Teaching plan and development direction, do a good job of teacher training. Through the planned training, to provide training opportunities for teachers to actively explore and other Colleges, research institutions and enterprises to cultivate talents in order to solve practical problems as the goal, to encourage teachers to undertake major research projects, through effective resources to train teachers, To maximize the enthusiasm of teachers, improve teacher ability, to provide teachers with the development platform.

\section{Conclusion}

It is necessary to design and implement the incentive mechanism and measures in the human 
resource management of Colleges based on the theory of motivation. In the process, we should pay attention to the research and analysis of the demand of faculty and the design of the incentive mechanism. The implementation of the process to grasp the correct principles will be able to effectively stimulate the creativity and motivation of faculty and promote the development of human resources management. Incentive theory plays an important role in the work of human resource management in Colleges. As a human resource management worker, the role of incentive theory should be recognized and the incentive theory can be infiltrated into human resource management, so that the incentive theory becomes the inexhaustible motive force for the continuous improvement of the quality of resource management.

\section{References}

[1] Cai Zhiwen. Study on the Research on the Incentive Management Mechanism of Teachers in China [J]. Journal of Shanxi Normal University, 2011 (S3)

[2] Hu Shu. China's university teachers incentive research summary [J]. Legal and social, 2008 (35)

[3] Ding Shihui. Encourage teachers of several methods [J]. Shanxi Education, 2008 (05)

[4] Yang Yan. College teachers incentive mechanism - based on the needs of college teachers analysis [J]. Read and write, 2008 (02)

[5] Liu Junyan. Foreign teacher quality and teacher incentive research summary [J]. Foreign Education Research, 2007 (10)

[6] Zhang Jizhen, Lu Jie. On the teacher knowledge management system under the teacher incentive method [J].Science and education, 2007 (06) 